\title{
Can a Cultural Variant Dedicated to Arab-Muslim Tourists Save the Tunisian Tourism Sector?
}

\author{
Rim Abdmouleh ${ }^{1} \cdot$ Maha Kalai $^{2}$
}

Received: 7 May 2018 / Accepted: 24 August 2020 / Published online: 1 September 2020

(C) The Author(s) 2020

\begin{abstract}
Unanimously recognised as a growing sector in today's world, cultural tourism continues to attract the attention of researchers seeking to exhume the mechanisms and dynamics that govern it. In terms of political and strategic choices, Tunisia is currently giving this sector an increasingly remarkable interest. It is in this perspective that we tried to carry out a survey that would highlight the opinions of Arab-Muslim visitors about cultural tourism in Tunisia. To this end, we relied on the principal component analysis and the probit models that we considered the most appropriate to deal with our problem. Using individual data from a sample of 300 Arab-Muslim tourists who visited Tunisia during the summer vacation of 2014, we tried to interpret the results that seemed very suggestive. Our analysis of the different results led us to deduce that it is difficult for the Tunisian destination to motivate the Arab-Muslim visitors by focusing on the cultural tourism (in its current state) and that it is not the best way to attract this category of tourists. In the light of the obtained results, we have proposed some solutions that could promote this destination and fructify this type of alternative tourism.
\end{abstract}

Keywords Seaside tourism $\cdot$ Cultural tourism $\cdot$ Tunisia tourism crisis $\cdot$ Arab-Muslim tourists

JEL Classification $\mathrm{C} 13 \cdot \mathrm{E} 03$

Rim Abdmouleh

rim-abdmouleh@hotmail.com

Maha Kalai

helali.kalai.maha@gmail.com

1 Department of Economics, Faculty of Economics and Management of Sfax, University of Sfax, 3.5 Gabes road, 3052 Sfax, Tunisia

2 Department of Quantitative Methods, Faculty of Economics and Management of Sfax, University of Sfax, Airfield Road Km 4, BP 1088, 3018 Sfax, Tunisia 


\section{Introduction}

Located south of the Mediterranean, Tunisia is famous for its coasts and beaches. This location explains the historical predilection for seaside tourism to the extent that even political strategies have highlighted this intrinsic link between Tunisian tourism and coastal areas. While seaside tourism has long been a real driver of the economy, employment and investment, it is going through a moment crisis now more and more salient especially after the revolution of January 14, 2011.

This crisis is aggravated by other factors such as competition with other destinations, the economic crisis, the degradation of equipment and infrastructure. As a result, the need to restructure tourism strategies is becoming an urgent necessity for Tunisia. Cultural tourism, therefore, seems to be a promising alternative that may open new horizons and expand the range of tourism products as well as target visitors. Thus, the present study raised questions and provided some solutions in order to highlight this alternative tourism for better social and economic outcomes. In other words, it is a question of revalorising the cultural potential that was long relegated to the seaside tourism.

Cultural products (monuments, historical sites, traditions, folklore) have great potential to make destinations more attractive. Similarly, since these products are not limited to coastal areas, this choice could expand the Tunisian tourist map by integrating the southern and western regions. In addition to the importance of this new concept of tourism at the sectoral level, it would be a solution aimed at reducing the impact of the social crisis in these disadvantaged regions victimised by regional inequalities in terms of growth, employment and living standard.

However, this new strategy requires great financial efforts and capital mobilisation to implement this kind of tourism. Given that the Tunisian state is going through a stifling financial crisis and that national and local private capitals are reluctant, foreign investment seems to be a fundamental means for promoting tourism. In this context, foreign capital from the Gulf countries seems to be a suitable solution.

In this research study, which is part of an economic and anthropological approach to destination tourism, we dealt with the actual as well as potential visitors who might be interested in the Tunisian destination. To this end, we analysed the tourists' motivations vis-à-vis the Tunisian destination by considering our questions and our investigations at the heart of the attractive cultural factors and focusing on other regions that are not exclusively seaside. The design of the approach and the interpretation of the results are based on an econometric model we considered relevant for the variables' analysis. It is the probit model that was first introduced by Bliss (1934).

Before presenting our hypothesis, we strongly believe that the tourism sector is considered as one of the fundamental drivers of economic and social development in Tunisia. In fact, this sector contributes with $7 \%$ to the GDP, generates 380,000 direct and indirect jobs and covers $56 \%$ of the country's trade deficit, according to Agence Foncière Touristique, AFT (2018).

Despite this economic weight, this sector has remained, for several decades, mainly seaside exhibiting numerous weaknesses and lingering deficiencies. Indeed, it remained a prisoner of a past development strategy, namely the standardised service inspired by the Fordist production model. This old-fashioned model drew its strength from lowcost mass production, which allowed for gains in scale and a regular and constantly 
increasing wage policy, which stimulated the consumption of the available products and services.

When Fordism, based on the principle "we sell what we produce", was dethroned in the early 1970s of the last century by Toyotism, implementing the principle of the production of "variety" and the motto "We produce what we sell", all sectors of the global economy have gradually aligned with this new maxim. The tourism sector has not been an exception and it is now the tastes of the visitors that dictate the nature of the product or service, its variety and its range. As a result, this shift in literature and economic approaches has stimulated many countries to provide product diversification efforts such as specific tourism services in countries that are classical tourist destinations.

Tunisia has not, unfortunately, taken into consideration these new economic approaches which are based on marketing strategies and the diversification of the proposed ranges. Indeed, it has continued investing in the low standardised range attracting only "poor" visitors spending little and being content with "natural" products (beach, sun, etc.) with low added value seasonally employed active population reluctant to become involved in providing better quality service. Similarly, despite the shy calls for and trials of a possible opening to an "alternative" or "cultural" or "ecological" tourism, attempts have remained reluctant.

This crisis worsened with the harsh competition with Mediterranean destinations that have close if not similar characteristics as the Tunisian model. According to the UNWTO (World Tourism Organization) (2011), Tunisia is, first and foremost, in competition with the countries surrounding the Mediterranean, mainly Morocco and Turkey and, to a lesser extent, Egypt. Turkey is the leading tourism destination with 34.083 million international tourists, followed by Egypt ( 9.497 million) then Morocco (9.342 million). Tunisia ranks fourth with 4.785 million, thus showing a deficit of more than 2 million compared with that in 2009, preceding Algeria, the fifth destination with 2.395 .

Despite the opacity of strategic tourism choices, the political and economic authorities were aware of the need to review the implemented strategies and introduce changes that could diversify tourism and its products and improve their profitability. In this respect, the Tunisian Ministry of Tourism launched a study to diagnose the situation and propose the necessary solutions in 2009. Just when it started the implementation of the recommendations of this study, a political earthquake hit the country at the end of December 2010. Thus, socio-political and especially ideological tensions put Tunisia back to the starting point, aggravating the already critical situation in this vital sector for the country.

Driven by the Islamist impulse that has dominated the Tunisian political scene, Tunisian tourism seems to want to convert into the "hallal" tourism in 2012-2013, in accordance with the precepts of the "correct" Islam according to the rudimentary point of view of the Islamists. This concept was developed in Tunisia relying on the Asian models such as Malaysia, Singapore and Turkey. Some Tunisian politicians have kept on feeding the idea that Arab-Muslim tourism is possible. As a result, several decisions issued by many officials at the top of the Tunisian state aimed at reconfiguring this sector. Having become a major issue of the overall development policy, religious pretexts tend to reign over the tourism sector and other closely tied fields such as the agri-food industry and wines. 
This tendency has generated odd paradoxes that risk driving this vital sector in the Tunisian economy to failure. The new leaders defend a tourism financed by an ArabMuslim capital whereas the entrepreneurs holding this capital, coming mainly from the Gulf countries, have not shown any particular interest in a cultural tourism and remain attracted by a seaside and nocturnal tourism which is based on the distraction and entertainment.

As far as the Gulf countries' consumers are concerned, they do not consider Tunisia a privileged destination nor its "cultural" tourist products as first choice goods and services. It is rather the neighbouring Algerian and Libyan tourists who flock in large numbers in Tunisia during the summer season and even the winter.

The second paradox that might be deduced here is that the last category forming nearly $40 \%$ of foreign visitors in 2009 has not shown any preference for this so-called cultural tourism, let alone the religious one. The desert, ksours, couscous, etc., can not play the role of a total escape for this category of visitors because such means do exist in abundance at home. Both of the Algerians and Libyans are attracted by seaside tourism as well as that related to health and therapy reasons.

In this context of crisis, and aware of the need to revolutionise the tourism strategies of the Tunisian destination, we tried, through our study, to answer the following fundamental hypothesis:

Hypothesis: cultural tourism might be the best way to attract Arab-Muslim tourists.

As already stated, Tunisia is a tourist destination that is famous for its coastline and beaches. However, these resources, subject of various strategies over time, continue to face an increasing harsh competition with other more attractive seaside resorts like Egypt and Morocco. This situation has become more serious following the world subprime crisis, political uncertainty and security precariousness after the revolution. It was even worsened by the degradation of equipment and infrastructure. As a result, re-examining Tunisia's products and target markets is now an absolute emergency. It is this problematic context that motivated us to elaborate the present study trying to examine the motivations of the Arab-Muslim tourists so as to allow us to overcome the shortcomings and develop this sector in order to overcome the difficult economic situation of our country.

Our study, therefore, focused on the key motivations of Arab-Muslims vis-à-vis Tunisian tourism while highlighting its undeniable impact on the promise of return, and of course, on economic growth. Arab-Muslim tourists may be interested in a cultural tourism which consists in encouraging new modes of creativity that have become essential for economic growth in Tunisia. Undeniably, this country is rich in monuments, historical sites, traditions and folklore. These assets are found, for example, in the south and west of the country. Hence, one may wonder about the impact of the promotion of an alternative tourism on these inland areas disadvantaged by economic growth and marginal development.

Given the importance of studies on the motivations of tourists in the planning of strategies targeting the promotion of cultural tourism, we tried to analyse, as a first step, the theoretical constructs of the visitors' behaviour. Research on tourism, in general, and cultural tourism in particular, can not be achieved in a comprehensive way if the tourist behaviour is not seriously taken into account through the tourist motivations. 
Our study, then, identified the relevant factors that would stimulate Arab-Muslim tourists and have an effect on the promise of return based on a probit econometric model and from the analysis of one principle variable: "the motives of Arab-Muslim tourists". The analysis of the results would allow us to draw some conclusions and propose some solutions helping us to modestly contribute to the restructuring of the Tunisian destination.

The rest of this paper was organised as follows: In the second section, we suggested a review of the literature on tourism and its components. The third section was devoted to our empirical analysis and interpretations. The main conclusions were drawn in the final section.

\section{Literature Review}

Before focusing on the different mutations of tourist products and the different theories of tourist motivation in relation to destination, it is important to highlight the role of tourism in terms of economic growth. Dimelli (2017) postulates that economic, social and environmental changes are, directly or indirectly, related to the rapid growth of tourism and to the country's long-run sustainability. Indeed, the recognition of tourism as a potential tool for economic growth has been formalised on the international stage by the United Nations Declaration on the Millennium Development Goals in 2000, as well as by holding the World Summit on Development (Johannesburg, 2002). This role has become an integral part of the development strategies implementation program.

In this perspective, MacCannell (1984) points out that tourism has become an economic growth generator at the end of the twentieth century. In addition, Gossling et al. (2008) state that tourism, thanks to its transversal nature and structuring capacity of territories, is one of the sectors that best allows the implementation of the economic growth approach in coherence with other spatial planning policies, infrastructure or social responsibility while ensuring its long-term development. It is for these reasons that Richards (2011) postulates that tourism contributes to growth from a different and more global approach. It cannot be seen as an isolated segment; it must be conceived as a mechanism for economic growth applicable to all types of tourist activities, acting on the behaviour of consumers and producers in the sector, and assuming their evolution, motivated by a culture of change.

During the 1990s, tourism became a highly specialised sector. Following the various socio-economic changes that have affected the world in general and the way of life in particular, we witnessed the use of various more specialised tourist products such as ecotourism, cultural tourism, sports tourism, health tourism and adventure tourism. Despite these changes, the tourism relative industry and the derived services have not adequately followed the diversity of tourism demand. Also, most research has shown that visitors are increasingly diverse in tourism behaviours, needs, wants and expectations.

As suggested in the literature, nothing is arbitrary in tourism since it focuses on promoting the destination and requires well thought out strategies and fairly lucid and pragmatic choices. From now on, the new tourist approaches have to be linked to the existing lifestyle and to the different specificities (demographic, psychological, cultural ...) of the various tourists targeted by the attraction and marketing strategies of the 
demographic destinations. From this view point, tourism poles can also serve as vehicles through which holidaymakers seek to satisfy their lifestyle needs (Mavragani and Lymperopoulos 2013).

That tourism offers individuals the opportunity to meet a variety of psychological needs is not new. Since the 1970s, researchers began to gather a body of knowledge that unveils the link between tourist behaviour and the psychological needs of potential tourists. Barbieri and Sotomayor (2013) proved that vacations offer individuals the opportunity to meet their needs. Similarly, Brochado et al. (2018) stated that visitors are motivated by such characteristics as sport, sex, education and income.

Olson and Dover (1979) defined the tourists' behaviour as an evaluation of a specific product or service. This means that a positive or negative evaluation would depend on the tourists' notion of satisfaction.

This primacy of the evaluation of the destination has grown tremendously with the development of new communication technologies and social networks. These have enabled the world to notice different types of evaluation-which are mostly pejorative as they depend on the visitors' satisfaction-spread fast through the social media.

Within this trend of thoughts, Lee et al. (2017) report that various analytical methods confirmed that online tourism information is related to offline visits, revealing some photo-sharing behaviour after the tour. Thus, promotional strategies must take into account the visitors' different reactions, displayed on networks and online pages after their journeys in order to determine their appreciations, their behaviour and their psychology deep structures. This would give a clear idea about their motivations.

Motivations are critically important for service quality and visitor satisfaction, according to Boulding et al.'s (1993) work on dissatisfaction. This author proposed that tourists form a normative motivation for future events regarding what is appropriate or deserved (Greg and van de Ark 2013). Motivation provides a tool to measure the tourist's satisfaction. According to Mill and Morrison (1985), motivation arises whenever an individual wishes to satisfy a need.

From the tourist perception, the fact that it is defined as a pressure concept, the motivation factor is important (Neuhofer et al. 2014). As for Eduardo and Tadeo (2018), they state that public diplomacy (PD) aims to attract a foreign audience through art, transmission of knowledge, media, language and foreign aid.

Several researchers noted that tourists have various motivations and that people can have different reasons for choosing either national or international holidays. Fadda and Sorensen's (2017) affirm that each destination offers a variety of products and services to attract visitors in such a way that each tourist is provided by an opportunity to choose among a set of various destinations.

Since motivation is a dynamic concept, it may vary from one person to another, from a market segment to another and from one place to another as a decision-making process for the next visit (Richards 2011). It is not surprising, therefore, that the concept of motivation is considered as a tourist market segmentation element in many empirical surveys, as mentioned by Crompton (1990).

Apart from motivation, different factors, such as age, income, personality, cost, distance, risk and motivation, may influence the choice of a destination. The literature on tourism highlights the importance of the push or pull factors when developing the tourists' motivations and choosing the holiday destinations (Crompton 1990). The 
"push" factors refer to the traveller's intangible and intrinsic desires like escapism, rest and relaxation, adventure, health or prestige.

Fadda (2017) focuses on sports in order to assess their ability to attract tourists to seaside destinations and strengthen economic development and tourism potential. He deduced that the visitor motivation is determined by "push" and "pull" motives.

A push model is a socio-psychological pattern that has always been implemented. From this point of view, one can elicit that consumers are "pushed" by their emotional needs to use a certain service or product during their visits. The emotional needs are relevant when it comes to seeking pleasure and choosing behaviour (Goossens 2000). The literature on the consumer's behaviour underlines that motivations might be interrelated as stated by Goodall (1988). People may travel to meet their physiological needs. Felice (2018) postulates that one of the most successful elements of the Japanese government is the soft power of food (washoku, traditional Japanese cuisine), climate and health or psychology (adventures and relaxation).

The "pull" factors, however, are essentially related to the attractiveness and tangible features of a given destination such as beaches, accommodation, recreational facilities and cultural and historical resources (Uysal et al. 1990). Mavragani (2015) argues that heritage has a significant effect on economic and cultural development.

Consequently, the evaluations of the corresponding tourist attributes as well as their usefulness could become crucial criteria in the final choice and ranking of a major destination. Towner and Milne (2017) insist on the fact that several attempts have been made to classify the major elements of a destination. Among these elements, we can cite the climate, ecology, culture, architecture, hospitality, transportation and recreation. The basic attributes of a destination are numerous and differ from one place to another (Mura and Tavokali 2015). Privileged sets and destination attributes can be adapted to specific visitors' psychological profiles. As an illustration, we can take Hakonsson et al.'s (1993) who cited a resting-exhaust group that prefers destinations offering a night life, entertainment, water sports, golf, tennis, fishing, shopping and sports games. Similarly, there are destinations that offer varied multi-products. Tourists could visit a destination during the summer just to relax, but others visit the same destination in the winter to seek adventure (Wolfram and Burnill-Mair 2012).

For the research on Tunisia, there are some studies that have investigated tourism by applying economic, sociological and management approaches. Zaiane (2004), for example, states that tourism and recreation have become a mass phenomenon, accessible to all, in varying degrees. The studies of Kassah (2008), Bourgou (2005) and Mzabi (1993) focused on the growth of seaside resorts. Here, we can cite the case of Bizerte port, north-east of Tunisia, which offers a relevant example of a coast which has been the subject of major urban and port development works since the end of the nineteenth century. The improvements on the site have resulted in a noticeable change in the coastal dynamics (Bourgou 2005). Mzabi (1993) also reviews some aspects of regional and local developments in Tunisia. According to Kassah (2008), the development of the Djerba tourist resort has had a remarkable influence on demographic plans and urban and social structures. This destination (Djerba) has become a symbolic setting conducive to dreams as suggested by the famous paraphrase of the "Isle of Dreams".

After this review of the literature on destination and motivation, it seems essential to focus on the notion of culture that is at the heart of our problem and hypothesis. 
Culture is a multipurpose concept which involves the values, morals, symbols, physical manifestations and behaviours governed by a particular worldview. In this context, Gullestrup (2006) considered culture in a clear process of values and worldviews that govern any society. This process includes observable habits and rituals determining social hierarchies, physical manifestations including items such as art, architecture and craft. According to Bourdieu (1986), tourists need to perceive the cultural aspects of a community in order to understand why these events create the cultural phenomenon.

According to many critics from De Kadt (1979) to Urry (1987), cultural tourism is part of the anthropological tourism. Reisinger (2011) suggests that it should be noted that a genuine cultural tourist should recognise the culture own differences and acts as an anthropologist who establishes a network of meanings not restricted to the eccentric differences which purpose is just a superficial entertainment.

In our empirical study, we opted for the probit model, applied to individual data, which makes it possible to concretise the forecast. The use of surveys with a large number of items, as representatives of a number of variables, requires the reduction of these variables (factorisation) to a small number of factors retrieving the maximum amount of information. The most used factorisation method in this type of data is the principal component analysis (PCA) (Benzécri 1973; Cibois 1984).

Among the most well-known studies, we can mention those of Berkson (1951) who referred mainly to the simple dichotomous probit model. Its first applications were mainly conducted in the field of biology, sociology and psychology. It was not until the 1970 s that this model was used to study economic data, especially relating to the tourism sector, after the publications of McFadden (1974) and Heckman (1976). It was found that the application of econometric techniques specific to qualitative variables on economic issues has largely contributed to improving the interpretation of simple models.

\section{Empirical Analysis}

As part of the main issue that focuses on the tourist destination and on the motivations of the real tourists (subject of our sample) and potential visitors (target tourists), the objective of our study was to detect whether cultural tourism could be an attraction factor to Arab-Muslim tourists from their motivations. Another goal was to determine the variables that affect the return promise using a probit logistic model through the robust command on the Stata 15.0 which would be estimated on the basis of the information collected from visitors.

\section{Variables and Methodology}

The data analysed in this study were based on information provided through a survey that revolves around 7 variables distributed on 300 Arab-Muslim tourists, who came to spend their holidays in Tunisia. This study was carried out during the 2014 summer holidays in hotels located in Sousse, Hammamet and Mahdia. These tourists were distributed as follows: 
- 100 tourists have resided at the hotel Houda Yassmine, Hammamet;

- 100 tourists who have resided at Dreams Beach Hotel, Sousse;

- 100 tourists who have resided at the Mahdia Beach hotel, Mahdia.

\section{As for the 7 variables, they are defined in Table 1 below.}

The breakdown was carried out in order to understand the motivations of ArabMuslim tourists, which will make it possible to measure whether cultural tourism would be the best way to attract these visitors to Tunisia and to recognise the variables that affect their return promise. In the same way, this breakdown would also clarify the impact of the regional differences on this promise.

In addition, the probit modelling admits, for the explained variable, the probability of the event occurrence, conditional on the exogenous variables. It consists of looking for the factors which would help to explain the return promise of the Arab-Muslim tourists to Tunisia. Furthermore, the probit estimates allow calculating the marginal

Table 1 The survey variables

V1 Tunisian attractions (V11 (sea, sun and sand), V12 (familya), V13 (culture)). This variable asks about the attractive factors that motivated the different tourists to visit Tunisia. It would allow us to evaluate the probability for an Arab-Muslim customer to revisit Tunisia. Similarly, the coexistence of the variables V11 and V13 would enable us to confront two fundamental attractive elements in our study: a "classical" factor, that of "sea, sun, and sand", and an alternative factor, that of "the culture".

V2 The attractive Tunisian tourist regions (V21 (Hammamet), V22 (Djerba), V23 (Sousse), V24 (Monastir), V25 (Tabarka), V26 (Kelibia), V27 (Mahdia)). We have tried to check whether the seaside areas still keep, as they used to, their attractive power. This variable would allow us to determine the preferred regions by visitors, which would help estimate the probability of revisiting Tunisia by this category of customers.

V3 Tunisian cultural discoveries (V31 (gastronomy), V32 (mosques), V33 (Sahara), V34 (relaxation) and V35 (monuments)). The purpose of these variables was to evaluate the impact of cultural discoveries on the visitors' motivation. Thanks to its factored nature, this variable makes it possible to give more precision on the attractive cultural elements and to know if this variable influences the probability of an Arab-Muslim customer of revisiting Tunisia.

V4 Tunisian cultural tourism. This variable is binary in nature. Thus, it consists of checking whether the tourist is generally interested in cultural tourism or not. This variable would study the cultural motivation and estimate the return promises for the Arab-Muslim customers.

V5 Tunisian south. This variable is binary in nature. This variable is in continuity with V2 (devoted to seaside regions). It is a question of checking if these customers intend to visit the Tunisian south to live a different experience from that of the seaside tourism. This variable allows us to estimate the probability of revisiting southern Tunisia.

V6 This variable is dedicated exclusively to customers who opt for the "no" answer at the V5 binary variable. This is to explain why these reluctant customers do not plan to revisit southern Tunisia. V6 collaborates with V2 and V5 to give us an idea about the attractive and unattractive regions to Arab-Muslim customers. In the same way, this would allow us to compare, in terms of customer motivation, between the seaside regions (V2) and the southern interior regions (V5 and V6).

V7 This variable is introduced to measure the promise of return to Tunisia in a general way which is of Boolean type ( 1 if the Arab-Muslim customer intends to revisit Tunisia and 0 if not). It allows detecting, at each step, its influence on the other exogenous variables of the model V1, V2, V3, V4, V5 and V6.

Source: The author's construction

a We mean by "family" the motivation of coming to Tunisia to spend pleasant moments with one's family (couples, children, parents, etc.). 
effects that generate proportions according to which each explanatory variable influences the probability that an Arab-Muslim tourist revisits Tunisia.

\section{The Factorisation Results and Interpretation}

The measurement scales of the variable "Arab-Muslim tourists' motivation" have to meet certain conditions. In this context, the factorial analysis involves the three following concepts: attractions, tourist regions and cultural discoveries.

The first concept, the Tunisian attractions, is presented by the variable V1 which consists of three sub-variables (V11, V12 and V13). It is important to check the reliability and validity of these items by using Cronbach's alpha to measure the variables' internal consistency, on the one hand, and the Kaiser-Meyer-Olkin (KMO) index to test the relevance of the PCA, on the other. Indeed, the factorisation generated a high reliability coefficient of about 0.87 and a good validity of about 0.75 (Table 2). These results allow us to move to factorisation using the PCA principles with which we applied the VARIMAX rotation. This factorisation enabled us to extract a common factor, denoted F1, which represents $86.8 \%$ of the total information.

The second concept, tourist regions, includes variable V2 which involves seven subvariables (V21, V22, V23, V24, V25, V26 and V27). We proceeded with the same steps as achieved with the previous variable. Reliability and validity were evaluated at 0.84 and 0.88 , respectively (Table 2). The good results of the tests allow us to move to factoring using the PCA principles with which we applied the VARIMAX rotation. This factorisation enabled us to extract a common factor, denoted F2, which represents $48.8 \%$ of the total information.

The third concept (cultural discoveries) includes variable V3 which consists of five sub-variables (V31, V32, V33, V34 and V35). The Cronbach reliability test shows a value of 0.72 and the KMO value is 0.66 . These results are satisfactory and allow us to move to factorisation. This factorisation made it possible to extract a common factor, denoted F3, which represents $57.1 \%$ of the total information.

\section{Testing the Impact of the "Motivations of Arab-Muslim Tourists" Variable on the Return Promise}

Our model is based on the probability whether an "Arab-Muslim tourist" will revisit Tunisia or not. This modelling allows having some clues about the elements influencing the return promise.

Table 2 Factorial analysis results

\begin{tabular}{clll}
\hline Factors & Cronbach's alpha & Kaiser-Meyer-Olkin & Explained variance \% \\
\hline F1 & 0.871 & 0.752 & 86.805 \\
F2 & 0.841 & 0.880 & 48.839 \\
F3 & 0.722 & 0.665 & 57.091 \\
\hline
\end{tabular}

Source: Author's construction on the basis of the SPSS software results 
Referring to the results obtained in the "The Factorisation Results and Interpretation" section, we estimated the impact of the "Arab-Muslim tourists" motivation on the promise to return using the following econometric model:

$$
\begin{aligned}
\text { Promise to return }_{\mathrm{i}}= & \beta_{0}+\beta_{1} \times F 1_{i}+\beta_{2} \times F 2_{i}+\beta_{3} \times F 3_{i}+\beta_{4} \times V 4_{i}+\beta_{5} \\
& \times V 5_{i}+\beta_{6} \times V 6_{i}+u_{i}
\end{aligned}
$$

where $u_{i}$ are the non-observed, independent and identically distributed error terms, of a variable $u$, which average is null, a constant variance $\sigma_{u}^{2}$ and $\beta_{i}, i=0,1, \ldots, 6$, which are the parameters to be estimated through the probit taking into account the individual heteroskedasticity problem.

Table 3 synthesises the estimation results of the link between the motivations of Arab-Muslim visitors and the return promise using the probit model.

According to the regression results, the Wald statistic has a value equal to 72.438. It is greater than the $95 \%$ quantile of the 6-degree chi-square law (i.e. 19.675). From this test at the $5 \%$ threshold, there is a presumption of global causality. In addition, the $p$ value that is 0.000 is less than 0.05 , which shows that the model is globally significant.

The results shown on Table 3 allowed us to deduce different characteristics of the Tunisian destination and outline some characteristics of the potential target tourists who would be motivated by a Tunisian cultural tourism provided by its southern regions:

\begin{tabular}{|c|c|c|c|c|}
\hline \multirow[t]{2}{*}{ Endogenous variable: promise of return } & \multicolumn{2}{|l|}{ Estimation } & \multicolumn{2}{|c|}{ Marginal effect } \\
\hline & Coefficient & $Z$ & Coefficient & $Z$ \\
\hline $\mathrm{F} 1$ & 0.218 & $3.63^{* * *}$ & 0.066 & $3.69^{* * * *}$ \\
\hline $\mathrm{F} 2$ & 0.004 & $2.03^{* *}$ & 0.001 & $2.03^{* *}$ \\
\hline F3 & 0.406 & $2.12^{* *}$ & 0.123 & $2.18^{* *}$ \\
\hline V4 & -0.094 & -0.68 & -0.028 & -0.68 \\
\hline V5 & -0.074 & -0.99 & -0.042 & -0.63 \\
\hline V6 & -0.084 & -0.58 & -0.018 & -0.58 \\
\hline Constant & -2.837 & -1.15 & & \\
\hline Wald $\chi^{2}(6)$ & $15.09 * * *$ & & & \\
\hline Number of observations & 300 & & & \\
\hline$\chi^{2} p$ value & 0.000 & & & \\
\hline Pseudo $R^{2}$ & 0.0985 & & & \\
\hline McFadden's adjusted $R^{2}$ & 0.06 & & & \\
\hline Log-likelihood intercept only & -93.153 & & & \\
\hline Log-likelihood full model & -56.934 & & & \\
\hline Likelihood ratio (6) & $72.438 * * *$ & & & \\
\hline
\end{tabular}

Table 3 Probit model estimation results

$*$, ** and *** at $10 \%, 5 \%$ and $1 \%$ significance

Source: Authors calculations from the database on Stata 15.0 
First, we found that the coefficient of the variable F1 "sea, sun, and sand" is highly significant, and the positive sign obtained is in line with our expectations. This is all the more true since the calculation of the marginal effect shows that the variable F1 increases the return promise by $6.6 \%$. The apparent satisfaction and its positive impact on the return promise should not be interpreted naively as if the Arab-Muslim tourists were passionate of the Tunisian "sea, sun and sand". Indeed, we cannot deny that the seaside regions are favoured at the level of growth and development. Consequently, the visitor experiences a more comfortable and pleasant stay since these coastal areas offer the different services that a tourist seeks without being exclusively attracted by the sea and the sand: other factors such as transport, communication services, cleanliness, security, follow-up, guide, car rental agencies and cruises play an important role, as well.

Second, we note that the coefficient of variable F2 "Hammamet" is highly significant, and the positive sign obtained is in line with our expectations. From the marginal effect, we can see that F2 variable increases the return promise by 0.1. The attraction of the Arab-Muslim tourists for the seaside tourism and resorts is an extension of the Tunisian traditional tourism. This aspect is a confirmation of the postulate that we have mentioned since our introduction, namely the primacy of seaside tourism.

This visitor's motivation has already been prepared by the marketing system. Certainly, the tourist is psychologically prepared for the pleasure that he will enjoy on the Tunisian coasts before even settling in these regions: images, photos, nudity, libertine lifestyle, ... This can be regarded as some kind of psychological conditioning exercised on the visitors at the time of the initial choice of the destination.

Third, the coefficient associated with variable F3, "gastronomy", is significantly different from zero. This is all the more true since the calculation of the marginal effect led us to understand that the F3 variable increases the return promise by $12.3 \%$. This variable shows that gastronomy plays a growing and essential role for the return promise and that the Arab-Muslims are very motivated by this cultural discovery. Therefore, in order to exploit this cultural component and offer new forms of experience, the emphasis has to be put on increasing micro-finances for small- and mediumsized enterprises involved in food production and cultural tourism. However, gastronomy is not enough to permanently attract the Arab-Muslim tourists. Despite the peculiarity of the Tunisian cuisine, it shares several common affinities with other Arab and Muslim cuisines. These similarities become more salient when it comes to the Maghreb cuisine, in this case Algeria, Libya and Morocco (sharing the couscous dish for example). Yet, the tourists who made up our initial sample are mainly Algerians and Libyans. This suggests that taking gastronomy as a permanent attractive factor remains precarious and unreliable.

Regarding gastronomy, therefore, it is necessary to focus on purely Tunisian dishes that form a kind of food folk-like traditional bread, dishes intrinsically Tunisian (lablebi, spicy and hot dishes). Similarly, we should not limit the gastronomic aspect to the food aspect only. Certainly, it would be fruitful to add experiences and joint activities such as trips to the suburbs or the desert.

\footnotetext{
${ }^{1}$ In the same way as Wagner (1977) who proved that sea, sun and sand offer individuals the opportunity to meet needs.
} 
Exhibitions describing food circuits from production to consumption could also be prearranged. This phenomenon is noticeable, even rather timidly, at the level of some cultural events related to gastronomy such as the festival of "Bsissa" and olive oil. In this context, Bourdieu (1986) emphasises the importance of safeguarding culinary heritage as a cultural tourism strategy. In order to develop a gastronomy-promoting strategy, it seems fruitful to encourage active agents in the culinary field. This development should not be restricted to hotels, but rather extended to other settings such as restaurants in the region, picnics in the wild with traditional meals for tourists, etc.

Fourth, the coefficient of variable V4 "Tunisian cultural tourism" has no influence on the return promise. This variable does not exert a significant attraction on ArabMuslim tourists. It is for this reason that our choice of seaside tourism as an indicator is not arbitrary. We tried to exploit the factors that contributed to the success of this type of tourism in order to apply them to the southern regions. In other words, a whole economic, social and urban system is urgently required in the disadvantaged regions to make the visit more enjoyable.

However, if the interaction between the "sea, sun, and sand" is the key to the promotion of seaside regions, the interaction between culture, heritage and landscape would be, potentially, an original tool that would allow inland areas to become more attractive. According to Goulding (1999), cultural tourism exists only through tourists who generally favour culture and enjoy experiences in culturally different places from their home countries.

Fifth, the coefficient of the variable V5 "southern Tunisia" has no influence on the return promise for Arab-Muslim tourists. Unlike seaside destinations, these regions have not been subject of the same advertising campaigns. On the contrary, in postrevolutionary Tunisia, the inner regions of the south have a negative connotation in the foreign media. Thus, they are associated with pejorative notions in the minds of consumers (virtual tourists) such as insecurity, terrorism, manifestation social, strikes, roadblocks and violence.

Sixth, the coefficient of variable V6 "the reason why Arab-Muslim tourists did not come to southern Tunisia" can be remarked to have no influence on the return promise. It also implies the necessity that the seaside-culture duality must be overcome. A successful and ambitious strategy should play on the interplay between the two factors. This strategy would create a sort of decompartmentalisation between the Tunisian regions. The more the Tunisian media focus on the contradiction between the coasts and the south, the more the visitors will misjudge the inner regions.

This interplay between seaside, cultural and Tunisian southern regions can be concretised at the level of the Tunisian islands. In this regard, an alternative tourism based on the island regions to the south (Djerba and Kerkennah) could revolutionise the Tunisian tourist map.

To sum up, we found that Arab-Muslims are not interested in cultural tourism, in its current state, from the non-significance of most of the explanatory variables chosen in this survey. However, according to the analysis of the variable "motives of ArabMuslim tourists", there are relevant factors which have an effect on the return promise like the seaside tourism (sea, sun and sand).

Once tourists perceive their travel experiences in a positive way, the satisfaction and reliability levels will increase. Tourists' satisfaction can be improved by an "attractive power". This is important, since a vibrant and sustainable tourism industry will make a 
significant contribution to the country's economic well-being. An in-depth understanding of tourists' motivations can help improve the quality of the visit and visitors' satisfaction. We can bet on island tourism which is distinguished by its particularity and attractive power in the world (Corsica, Hawaii, Sicily ...). Similarly, on the anthropological level, the inhabitants of the islands are distinguished by a rather unique cultural heritage.

For the Tunisian case, Djerba offers this cultural and even religious particularity (cohabitation between Muslims and Jews, handicrafts ...). In addition, and despite the limits of its beaches, Kerkennah archipelago offers quite attractive cultural factors as the specific agricultural heritage, its special gastronomy, fishing (Chraafi which is a world cultural heritage), the family industry oriented towards maritime activities and so on.

In a nutshell, Tunisian tourism must be the subject of a full restructuring project that would give cultural factors their true importance and scope. It is a question of joining fruitfully the promotion of the southern regions (at the level of the development plans) and that of the cultural tourism.

\section{Conclusion}

In the light of the different results we have reached, we can deduce that cultural tourism, in its current form, does not represent a real determining motivation for Arab-Muslim visitors. The socio-econometric evolution of the data has shown that the variables related to cultural tourism as well as the southern regions do not have an impact on the return promise.

While being aware of the limitations of our study, we can say that the proposed solutions throughout this study will not solve the problems faced by the tourism sector. In both cases, our study, together with the many other publications on tourism, has tried to unveil a few factors that we considered relevant. This work also outlined some recommendations for maintaining economic growth. Ultimately, this research opens the prospect of a more in-depth study that will enable us and other researchers to solve the problem of tourism growth taking into account the factors we have identified.

This article, in our viewpoint, is only a reflection on a Tunisian alternative tourism in general and on the southern regions in particular. In order to identify the different facets of this issue, we are in the process of completing a second article on Arab-Muslim investors (especially those of the Gulf). We have to admit that the questionnaire sample of the 300 interviewed tourists might be the main shortcoming of this study. We are thinking of relying on a greater number of visitors with a greater diversification of the targeted nationalities so as to get a more reliable database that could lead to better and more robust conclusions.

Open Access This article is licensed under a Creative Commons Attribution 4.0 International License, which permits use, sharing, adaptation, distribution and reproduction in any medium or format, as long as you give appropriate credit to the original author(s) and the source, provide a link to the Creative Commons licence, and indicate if changes were made. The images or other third party material in this article are included in the article's Creative Commons licence, unless indicated otherwise in a credit line to the material. If material is not included in the article's Creative Commons licence and your intended use is not permitted by statutory regulation or exceeds the permitted use, you will need to obtain permission directly from the copyright holder. To view a copy of this licence, visit http://creativecommons.org/licenses/by/4.0/. 


\section{References}

Avocevou, C., (2003). Déterminants Socio-économiques de l'accès au micro crédit en milieu rural: cas de la commune de Zogbodomey. Thèse d'Ingénieur Agronome Option Economie Socio Anthropologie et Communication, Paris, p.85.

Barbieri, C., \& Sotomayor, S. (2013). Surf travel behavior and destination preference: an application of the serious leisure inventory and measure. Tourism Management, 35, 111-121.

Benzécri, J.P., (1973). L'Analyse des Données, t.I: Taxinomie; t.II: L’Analyse des Correspondances, Bordas, Paris (1re édition 1973, 2e édition 1976, 3e édition 1980, 4e édition 1982).

Berkson, J. (1951). Why I prefer logits to probits. Biometrics, Elsevier, Oxford, 7(4), 327-330.

Bliss, C. I. (1934). The method of probits. Science, AAAS, USA, 79(2037), 38-39.

Boulding, W. A., Staelin, R. K., \& Valarie, A. Z. (1993). A dynamic process model of service quality, from expectations to behavioral intentions. Journal of Marketing Research, Elsevier, Oxford, 67(4), 420-450.

Bourdieu, P., (1986). The forms of capital. Handbook of theory and research for the sociology of education, Greenwood; New York, 54(7), 241-258.

Bourgou, M., 2005. Les plages, Impact des aménagements touristiques et portuaires sur leur évolution récente. Exemples tunisiens, Série géographique, Cérés, Tunis, 255-265.

Brochado, A., Stoleriu, O., \& Lupu, C. (2018). Surf camp experiences. Journal of Sport and Tourist, 22(1), 21-41.

Cibois, P. (1984). L'analyse des données en sociologie. Le Sociologue: PUF.

Crompton, J.L., (1990). Tourism research: redirections for the nineties. In Proceedings of the National Outdoor Recreation Trends Symposium III, J. T. O Leary, Indianapolis, 19(2), 944-955.

Dann, P. (1988). Tourist motivation: an appraisal. Annals of Tourism Research, Elsevier, Oxford, 8(2), 187219.

De Kadt, E., 1979. Perspectives on the social and cultural effects of tourism in developing countries. Oxford University Press, Elsevier, Oxford, 143(8), 18-25.

Dimelli, D. P. (2017). The effects of tourism in Greek insular settlements and the role of spatial planning. Journal of the Knowledge Economy, Springer, Oxford, 8(1), 319-336.

Eduardo, L., \& Tadeo, H. (2018). Public diplomacy, soft power and language: the case of the Korean language in Mexico City. Journal of Contemporary Eastern Asia, Elsevier, Oxford, 17(1), 27-49.

Fadda, F., (2017). Tourism from water boardsports: evidence from the emerging destination of Sardinia. Journal of the Knowledge Economy, Springer, Oxford, 1-18.

Fadda, N., \& Sorensen, J. F. L. (2017). The importance of destination attractiveness and entrepreneurial orientation in explaining firm performance in the Sardinian accommodation sector. International Journal of Contemporary Hospitality Management, 29(6), 1684-1702.

Felice, F. (2018). Japan's gastro diplomacy as soft power: global washoku and national food security. Journal of Contemporary Eastern Asia, Elsevier, Oxford, 17(1), 153-146.

Goodall, J. (1988). In the shadow of man. Weidenfeld and Nicolson, Elsevier, Oxford, 24(7), 125-245.

Goossens, C. (2000). Tourism information and pleasure motivation. Annals of Tourism Research, Elsevier, Oxford, 24(2), 283-304.

Gossling, S., Hall, M., \& Weaver, D. (2008). Sustainable tourism futures: perspectives on systems. Restructuring and Innovations, Routledge, London, 12(3), 112-143.

Goulding, C. (1999). Contemporary museum culture and consumer behavior. Journal of Marketing Management, Elsevier, Oxford, 15(1), 647-671.

Greg, R., \& van de Ark, L. A. (2013). Dimensions of cultural consumption among tourists. Tourism Management, Elsevier, Oxford, 37(11), 71-76.

Gullestrup, H. (2006). Cultural analysis. Towrds cross-cultural understanding (pp. 345-381). Hans, Alborg: Alborg Universitetsorlag.

Hakonsson, D. J. F., Nielsen, C. C., Snow, \& Ulhoi, J. (1993). New approaches to organization design: theory and practice of adaptive. Organizations Working Together, Sage, London, 32(4), 79-86.

Heckman, J. (1976). The common structure of statistical models of truncation, sample selection and limited dependent variables and a simple estimator for such models. Annals of Economic and Social Measurement, NBER, USA, 5(4), 475-492.

Kassah, A. (2008). L'ile de Djerba: tourisme, environnement et patrimoine (pp. 213-265). Cérés, Tunis: Environnement et patrimoine.

Lee, M. K., Yoon, H. Y., \& Park, H. W. (2017). From online via offline to online: how online visibility of tourism information shapes and is shaped by offline visits. Journal of Travel \& Tourism Marketing, Elsevier, Oxford, 34(9), 1143-1154. 
MacCannell, D. (1984). Reconstructed ethnicity: tourism and cultural identity in third world communities. Annals of Tourism Research, Elsevier, Oxford, 11(3), 375-391.

Mavragani, E., (2015), Greek museums and tourists' perceptions: an empirical research, Journal of the Knowledge Economy, springer, Oxford, 1-14.

Mavragani, E., \& Lymperopoulos, C. (2013). Factors affecting museum visitors satisfaction: the case of Greek museums. Tourismos, 8(2), 271-287.

McFadden, D., (1974). Conditional logit analysis of qualitative choice behavior: In Frontiers in econometrics. Academic Press, ed. P. Zarembka, New York, 10(2), 105-142.

Mill, R.C., and A. Morrison, (1985). The tourism system: an introductory text. Englewood Cliffs, Prentice-Hall International, Oxford, 15(7), 407-477.

Mura, P., \& Tavokali, R. (2015). Journeys in second life' - Iranian Muslim women's behaviour in virtual tourist destinations. Tourism Management, Elsevier, Oxford, 46(11), 398-407.

Mzabi, H., (1993). La Tunisie du Sud-Est: géographie d'une région fragile. Marginale et dépendante, Pub. Université Tunis, Tunis, 685-693.

Neuhofer, B., Buhalis, D., \& Ladkin, A. (2014). The technology enhanced tourist experience. International Journal of Tourism Research, Berlin, Springer, 16(4), 340-350.

Olson, J. C., \& Dover, P. A. (1979). Disconfirmation of consumer expectations through product trial. Journal of Applied Psychology, Elsevier, Oxford, 64(2), 179-189.

Reisinger, Y. (2011). Tourist-host contact as a part of cultural tourism. World Leisure and Recreation, Elsevier, Oxford, 36(2), 24-28.

Richards, G. (2011). Creativity and tourism: the state of the art. Annals of Tourism Research, Elsevier, Oxford, $38(4), 1225-1253$.

Towner, N., \& Milne, S. (2017). Sustainable surfing tourism development in the Mentawai Islands, Indonesia: local stakeholder perspectives. Tourism Planning and Development, 14(4), 503-526.

Urry, J. (1987). Some social and spatial aspects of services. Environment and Planning D: Society and Space, Pion, Oxford, 43(7), 5-26.

Uysal, M., Zimmerer, P., \& Bonn, M. A. (1990). Marketing resorts to the "gray" traveller. Leisure information Quaterly, Clemeson, USA, 16(4), 4-7.

Wagner, U., (1977). Out of time and place: mass tourism and charter trips. University Press, Elsevier, Oxford, 42(2), 173-190.

Wolfram, G., \& Burnill-Mair, C. (2012). The tactical tourist growing self-awareness. The Routledge Handbook of Cultural Tourism, Routledge Handbook, Berlin, 45(19), 361-368.

Zaiane, S. (2004). Introduction, Tourisme et Loisirs dans les parcs nationaux tunisiens (pp. 12-25). Tunis: Centre de Publication Universitaire.

Publisher's Note Springer Nature remains neutral with regard to jurisdictional claims in published maps and institutional affiliations. 